\title{
Plantar Fibromatosis
}

National Cancer Institute

\section{Source}

National Cancer Institute. Plantar Fibromatosis. NCI Thesaurus. Code C4680.

A superficial fibromatosis arising from soft tissue of the plantar regions. It is

characterized by the presence of spindle-shaped fibroblasts, hypercellularity, and an infiltrative growth pattern. 